\title{
HERNÁN GORTÉS EN DOS POEMAS DEL SIGLO DE ORO
}

Si los méritos artísticos de los poemas que cantan la hazaña de Cortés se prestan a discusión, no puede decirse, en cambio, que le hayan faltado poetas. Baste recordar que en el mismo siglo en que se llevó a cabo la conquista de la Nueva España hay ya tres que se inspiran en ella para escribir poemas épicos de cierta envergadura: Francisco de Terrazas, Gabriel Lobo Lasso de la Vega y Antonio de Saavedra Guzmán ${ }^{1}$. Por cierto que el segundo de estos poetas cantó la empresa cortesiana en dos versiones sucesivas, a cuál más voluminosa.

Pero ahora nos limitaremos a dos autores en cuyas obras la conquista de la Nueva España aparece de manera un tanto marginal. No escogen ellos el tema: más bien se les impone éste por sí mismo. Nos referimos a Luis Zapata y a Juan de Castellanos, cuyos poemas, de $15^{66}$ y de $15^{89}$ respectivamente ${ }^{2}$, se adelantan en fecha de apa-

1 Francisco de Terrazas es autor de un inconcluso Nuevo Mundo y conquista, del cual se conservan algunos fragmentos a través de un manuscrito de Baltasar Dorantes de Carranza, ejecutado a principios del siglo xvn y resumen, al parecer, de un original más extenso. José María de Ágreda y Sánchez lo sacó a luz con el título de Sumaria relación de las cosas de la Nueva España, con noticia individual de los descendientes legitimos de los conquistadores y primeros pobladores españoles, México, 1902. Los fragmentos que parecen haber formado parte del Nuevo Mundo y conquista pueden verse en las Poesías de Francisco de Terrazas, ed. A. Castro Leal, México, 1941. - Gabriel Lobo LAsso de LA VEGa escribió una Primera parte de Cortés valeroso, y Mexicana, Madrid (Pedro Madrigal), 1588, y una segunda parte -que viene a ser revisión y versión definitiva de la anterior- titulada Mexicana, Madrid (Luis Sánchez), 1594. (Ambos son libros raros; actualmente preparamos una edición de la versión definitiva). - El poema de Antonio de SaAvedra Guzmán se intitula El peregrino indiano, Madrid (Pedro Madrigal), 1599. Francisco García Icazbalceta lo reprodujo en 1880 .

${ }^{2}$ El poema de Zapata se publicó después de trece años de elaboración. "Están fechadas, la dedicatoria del poema, en Madrid a $1^{\circ}$ de febrero de ${ }_{15}^{6} 5$, y la censura de fray Juan de Robles a 8 de marzo. Creo, pues, que Zapata concluyó su obra en los últimos meses del año anterior" (JuAN MEń́ndez Pidal, "Discurso leído ante la Real Academia Española", enero de 1915, en los Discursos de la R. A. E., t. 3, Madrid, 1915, p. 54, nota). - En ${ }_{15}^{89}$ se publicó la Primera parte del poema de Castellanos, que es la que aquí nos interesa. El doctor Caracciolo Parra, cuyo prólogo a la edición de Castellanos es el mejor trabajo cronológico, llega a las siguientes conclusiones, basadas en 
rición al del primero de los tres autores arriba mencionados. Además, varias circunstancias secundarias establecen de inmediato un contraste entre ellos y el novohispano Terrazas. Zapata y Castellanos son españoles $-\mathrm{y}$ andaluces, por más señas ${ }^{3}-$, ambos ven sus obras publicadas durante su vida, y en ellas el propósito del autor no se encamina de antemano a narrar las hazañas de Cortés. El palaciego Zapata se propone cantar "las cosas del emperador nuestro señor, don Carlos", por lo cual -añade en la "Dedicatoria"- "hize en muchos días y en muchos años... este mi libro, que por no le quitar su nombre propio, le llamo Carlo y famoso" "; y Castellanos dirige sus esfuerzos "a sacar del sepulcro del olvido / a quien merece bien eterna fama" ( $(\mathbf{1}, \mathbf{1}$, canto 1$)$. Pero en ambas obras el peso de la historia impone sobre el autor su fuerza abrumadora, dando al traste, en parte, con la intención primera y explícita: Cortés y su empresa acaban por irrumpir en el poema.

En este punto cesan las coincidencias. El tema cortesiano recibe en nuestros dos autores tratamientos distintos, interesantes en sí y también desde el punto de vista de la épica en general y de la española en particular. En el limitado círculo que nos hemos trazado se pueden apreciar características que responden a momentos polares en la evolución de la epopeya española del Siglo de Oro, señalada en una breve nota por Menéndez Pelayo:

Sobre la poesía épica dominaron en el siglo xvi dos escuelas contrapuestas, la que pudiéramos llamar histórica, y la novelesca o fantástica. Los principios de esta segunda pueden verse expuestos (mezclados, en verdad, con los de la escuela alegórica) en el prólogo del Bernardo, de Valbuena, el más feliz de los imitadores del Ariosto (1624). Valbuena, fundado en la autoridad de Aristóteles, excluye de los dominios poéticos "la historia verdadera, que no es sujeto de poesía... Porque la poesía ha de ser imitación de verdad, pero no la misma verdad... y y así, para mi obra, no hace al caso que las tradiciones que en ella sigo sean ciertas o fabulosas, que

parte en los datos que el propio poeta ofrece a lo largo de su obra: "Entre $15^{81}$ y $15^{83}$, ya tenía terminada... la Primera parte e iba por la elegía $m$ de la Segunda... El manuscrito de esta Primera parte, perdido hoy, fue trasmitido a España por el poeta, allá por la octava década del siglo xvi. Aprobado por Agustín de Zárate, censor comisionado por el Consejo regio, fue estampado en Madrid en 1589 en casa de la viuda de Alonso Gómez, impresor de Su Majestad" (Obras de Juan de Castellanos, t. 1, Caracas, 1930, p. xlviii y nota). Nuestras citas de las Elegias proceden del tomo 4 de la $B A A E E$.

3 Zapata nació en Llerena (J. Menéndez Pidal, loe. cit., p. 11). A Castellanos se le tuvo hasta bien entrado el siglo xIx por nacido en Tunja (Colombia). Ahora se sabe con certeza que nació en Alanís (Sevilla). Para este y otros puntos oscuros de la biografía de Castellanos, cf. Raimundo Rivas, Los fundadores de Bogotá, Bogotá, 1938, t. 1, pp. 86-110 [reproduce los argumentos de

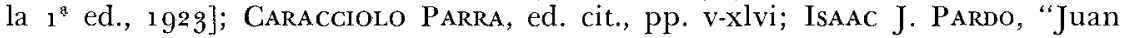
de Castellanos", $R N C$, 1955, núm 109, pp. 58-78.

4 Cit. por J. Menéndez Pidal, "Discurso...", p. 42, nota 2. 
cuanto menos tuvieren de historia y más de invención verisímil, tanto más se habrá llegado a la perfección que deseo..." Por el contrario, Baltasar de Escobar, en una especie de discurso o tratado sobre el poema épico que precede al Montserrate del capitán Virués, en la edición milanesa de 1602 , recomienda como principal materia épica los asuntos históricos libre y poéticamente tratados... Estas dos teorías explican la elaboración de todos nuestros poemas por más de dos siglos 5 .

Fundado en este primer deslinde, Van Horne observa que los prólogos de la Carolea de Sempere (1560), del Carlo famoso (1565) y de la primera edición de la Araucana (1569) proclaman la adhesión de los autores a la "historia verdadera", mientras que a finales del siglo la escuela fantástica, "establecida en realidad por las primeras imitaciones de Boiardo y Ariosto", estaba ya ganando terreno a expensas de la escuela histórica, según se ve por el aumento de episodios novelescos en las adiciones de Ercilla a la Araucana y por los cambios que ofrece la segunda edición de la Mexicana de Lobo Lasso de la Vega con respecto a la primera ${ }^{6}$.

No pretendemos refutar aquí a Van Horne ; sin embargo, conviene observar que, en lo tocante a Cortés, Zapata no cumple rigurosamente lo prometido en el prólogo. El marco del poema es histórico, sí, pero dentro de él, el poeta se permite alterar detalles y aun introducir episodios ficticios que de fantásticos rayan en lo grotesco. La historicidad del Carlo famoso sufre en este punto una quiebra, más evidente aún si se lo compara con el poema de Castellanos que, aunque mucho más tardío, se ciñe a la historia sin desviarse de ella un ápice. De hecho, la parte cortesiana del Carlo famoso $^{8}$ no es propiamente histórica, sino que tiende a un hibridismo en el que podemos ver ya un brote primerizo de la escuela fantástica.

5 M. Menéndez Pelayo, Historia de las ideas estéticas en España, t. 2, Madrid, 1884 , p. $3^{61}$, nota.

"John VAN Horne, "El Bernardo of Bernardo de Balbuena: A study of the poem with particular attention to its relations to the epics of Boiardo and Ariosto and to its significance in the Spanish Renaissance", Univ. of Illinois Studies in. Lang. and Lit., 12 (1927), 151-152. Ya había desarrollado esta idea en sus "Notes on sixteenth-century Spanish narrative poets", $P h Q, 4$ (1925), 241-244.

7 Y menos aún después de leer esta salvedad que él mismo hace: "But this discussion must not be prolongued here. Much investigation will be needed before the history of Renaissance Spanish epic poetry or epic criticism can be written" ("El Bernardo...", p. 152).

${ }^{8}$ Nos referimos a los cantos XI, XII y XIII (con 48, 109 y 44 octavas respectivamente, o sea un total de 201). Sólo 37 octavas del canto XI tienen por tema a Colón y el descubrimiento del Nuevo Mundo, y esto como introducción necesaria a las hazañas de Cortés. La desproporción en detrimento de Colón no se le ha escapado a Leicester Bradner, "Columbus in sixteenth-century poetry", Essays honoring Lawrence C. Wroth, Portland (Maine), 1951, p. 27, 
Pese al título del poema y a la declaración de la "Dedicatoria", el emperador Carlos $V$ queda reducido en esta parte a un papel secundario y pasivo: mero oyente del relato que hace uno de los emisarios de Cortés. Ciertamente, el poeta se proponía cantar "las cosas del Emperador", y entre ellas cabía una mención de sus extensos dominios, uno de los cuales era el Nuevo Mundo; pero esa atención minuciosa y sostenida a la figura de Hernán Cortés, que acaba por desplazar a la del Emperador, no parece justificarse, a primera vista, dentro de la economía del poema. Es como si el brillante relieve histórico de la hazaña del conquistador obligase al poeta, aun a pesar suyo, a concederle ese papel preeminente. $Y$, en este caso, ello tiene lugar sin que aparezca Cortés mismo, pues sus hazañas son expuestas indirectamente por medio de un relato. La escena en que éste se desarrolla -en la corte y ante gran número de cortesanos- tiene reminiscencias de los poemas caballerescos. Varios amigos de Cortés han venido a interceder por Cortés en sus pleitos con Velázquez, y Francisco de Montejo, “el que más era dellos elocuente", se encarga de hacer la exposición de los hechos. Para no omitir nada, comienza con el descubrimiento de las Indias y habla de Colón y de sus viajes ${ }^{9}$. A esto sigue la infancia y mocedad de Cortés, las circunstancias que rodearon su viaje a las Indias, la expedición a Yucatán, el encuentro con Jerónimo de Aguilar, la jornada de Potonchán y la cruenta batalla de Cintla. El largo episodio termina con la entrevista de Cortés y Teudilli (emisario de Moctezuma) y la destrucción de las naves.

La pauta histórica que sigue Zapata es la que le ofrecía López de Gómara en su Conquista de México, según lo ha destacado Medina en las notas de su edición de esta parte del Carlo famoso ${ }^{10}$. Pensando tal vez en las concordancias apuntadas por Medina, dice Morínigo que "el poema sigue paso a paso" (subrayamos nosotros) la Historia de Gómara ${ }^{11}$. Sin embargo, como ya hemos dicho, Zapata encuentra estrechos los límites del marco histórico. Si su habilidad poética queda por debajo de la discreta de un Terrazas o la media-

nota 7, quien después de destacar las Elegias de Castellanos como “sole Spanish poem before $\mathbf{1 6 0 0}$ to celebrate Columbus", advierte: "Although Luis Zapata's Carlo famoso, $15^{66}$, devotes one of its fifty cantos to Columbus, it subordinates him to Cortés, who gets two".

- Obsérvese, aun en este detalle formal, la dependencia de Colón respecto de Cortés: Zapata describe simplemente el escenario (las Indias descubiertas por el Almirante) para pasar luego al relato principal (la empresa de Cortés).

${ }^{10}$ Como la edición de $15^{66}$ es de muy difícil acceso y no hay, que sepamos, otra completa del Carlo famoso, nos hemos servido de la parcial de José ToRibio Medina, El primer poema que trata del descubrimiento del Nuevo Mundo. Reimpresión de la parte correspondiente del "Carlo famoso", Santiago de Chile, 1916.

${ }^{11}$ Marcos A. Morínigo, América en el teatro de Lope de Vega, Buenos Aires, 1946 , p. 48 . 
nísima de un Castellanos, su escrúpulo en materias históricas es más exiguo aún. Cuando de Cortés se trata, la imaginación de don Luis no se para en barras y, sin alcanzar la más modesta elevación poéti$\mathrm{ca}^{12}$, tergiversa los hechos con escaso discernimiento artístico, movido como por un afán de dar "sensacionalismo" al relato. Podrá ser un tanto dramática la escena en que Montejo deja al Emperador y a los cortesanos atónitos y pendientes de sus palabras, pero su valor histórico es muy escaso. Montejo y Portocarrero tuvieron que salvar muchos obstáculos para que el Emperador los escuchara, si bien, una vez logrado esto, pudieron vencer el antagonismo oficial. Peor todavía es el relato de la permanencia de Cortés en Cuba y de sus desavenencias con Velázquez, que se reduce a tres anodinas octavas (XII, 14-16); además, Zapata presenta de pronto a Cortés al frente de la flota, como si la hubiese organizado por su cuenta y sin la participación de Velázquez (XII, 18). El encuentro con Jerónimo de Aguilar y la relación de este náufrago, episodios que en Terrazas rayan en patetismo aunque el autor no se desvía de la historia, están deslucidos aquí a pesar del intento de hacer sensacional el suceso presentando a Aguilar como escapado apenas de una muerte horrorosa a manos de los indios antropófagos ${ }^{13}$. Y al narrar la batalla de Cintla, Zapata inventa sin necesidad nombres e incidentes. $\mathrm{Ni}$ en López de Gómara ni en Bernal Díaz del Castillo, que tanta gala hace de su buena memoria -sobre todo si con ello cree corregir algún desliz del cronista de Cortés-, hay la menor alusión a la muerte de un Acevedo, un Andino y un León, ni a las heridas de Olid, Portocarrero y Ordás. Un Luis y un Francisco de Acevedo y un Álvaro León figuran entre los que vinieron con Cortés ${ }^{14}$, sin que se

12 En Terrazas, son bastante estimables los pasajes dedicados a la pareja de enamorados Huitzel y Quetzal, o al encuentro de Cortés con Jerónimo de Aguilar. En cuanto a Castellanos, el relativo mérito del pasaje que narra el naufragio y salvamento de Alonso de Zuazo y sus compañeros ha sido destacado, entre otros, por Menéndez Pelayo, Antologia de poetas hispanoamericanos, t. 3, Madrid, 1894, p. xv.

${ }^{13}$ En realidad, después de escapar de su prisión, Aguilar y sus compañeros cayeron en manos de "otro cacique enemigo de aquél, y hombre humano, que se dice Aquincuz, señor de Xamanzana" y, muerto éste, pasaron a poder de Taxmar, su sucesor (Francisco López DE Gómara, Conquista de México, $B A A E E$, t. 22, p. 304a).

${ }^{14}$ En el "Apéndice" de Manuel Orozco y Berra que Ágreda y Sánchez. incluye en su ed. de Dorantes de Carranza, Sumaria relación..., pp. 361 y 370 (de ese "Apéndice" hay edición aparte: MANuel Orozco y Berra, Los conquistadores de México, México, 1938). Francisco A. DE Icaza, Diccionario auto. biográfico de conquistadores y pobladores de Nueva España, Madrid, 1923, t. 1, p. 6o, y t. 2, p. 271, reproduce las informaciones de un Álvaro de León que "pasó a esta Nueua Spaña con Pánfilo de Naruáez" y de un Hernando de Azeuedo "que á veynte años que pasó a esta Nueua Spaña, y siruió a $\mathrm{Su}$ Magestad en la conquista de la Nueua Galizia”. 
sepan más detalles sobre ellos; el nombre de Andino no aparece siquiera en las listas.

Pero todas estas inexactitudes de detalle son poca cosa en comparación de las exageraciones grotescas en que a veces incurre Zapata. Terrazas, sin apartarse esencialmente de la historia, logra un pasaje estimable cuando presenta la conversión de los indios de Cozumel tras una convincente alocución de Cortés ${ }^{15}$. Al tratar el mismo episodio, Zapata se proyecta hacia la tradición caballeresca -al parecer, fue traductor él mismo del Orlando furioso- y hace trabar a Cortés descomunal batalla con

un águila y un pez, dos monstruos fieros,

que no salía la gente, amedrentada

del águila a los campos placenteros,

ni del tiburón crudo que temían

al mar o ríos llegar no se atrevían (XII, 29) ${ }^{16}$.

Vencidos los dos monstruos, los agradecidos indios destruyen los ídolos, y el intrépido libertador pone en su lugar una cruz y una imagen de la Virgen.

En autor de mejores dotes, las escenas del combate se hubieran prestado a impresionantes descripciones y novedosas imágenes que distrajeran al lector de lo absurdo de la trama; pero Zapata, mejor prosista que poeta, como puede verse por su Miscelánea, no alcanza siquiera una medianía pasadera. Sus versos amazacotados, "que no serían más duros aunque fuesen de piedra berroqueña" 17 , están trabajosamente sometidos a la disciplina de la rima, y los escasos y poco originales símiles dejan traslucir siempre sus aficiones venatorias. Sin embargo, por desproporcionado y grotesco que resulte el empleo

${ }^{15}$ Pasaje núm. 13 en la ed. cit. de Castro Leal, que comienza: "Después que fue acabada la comida..."

${ }_{16}$ Sobre la "traducción del Orlando que escribía Zapata por entonces [1549], y que acaso dejó sin concluir", véase J. Menéndez Pidal, loc. cit., pp. 36-37. Por lo demás, las luchas con monstruos o animales salvajes abundan en los poemas caballerescos. Cf. el Morgante de Pulci: doma de un caballo por Rinaldo (canto XIII); Morgante mata un cocodrilo y una ballena (XIX y XX), y Rinaldo un dragón (XXI). En el Orlando innamorato de Boiardo, canto IX del Primer libro, Rinaldo sostiene una larga lucha y vence a un demonio de figura monstruosa. Pero el antecedente directo de la lucha con el tiburón, sin excluir los detalles del barquichuelo y el ancla, está en el canto XI del Orlando furioso (lucha con la Orca). El precedente histórico es la pesca del tiburón que menciona López de Gómara, ed. cit., pp. 305-3o6 (cf. en particular: “...que se come un hombre, como quiso hacer uno al calachuní de Acuzamil, que le cortó los dedos de un pie cuando no lo pudo llevar entero").

17 Palabras de F. Ronríguez Marín en su edición póstuma del Quijote, t. I, Madrid, 1947, p. 230, nota 1. Lo que no empece para que enmiende a Pellicer y Clemencín (y con ellos a J. Menéndez Pidal y Medina), quienes creyeron ver una errata en el "Luis de Ávila" mencionado por Cervantes y, en consecuencia, una condena al fuego del poema de Zapata. 
de tales fantasías para dar a Cortés una talla heroica sobrehumana, las circunstancias de los combates con los monstruos demuestran que Zapata no andaba del todo descaminado en su concepción del conquistador de México. En ambos combates procede Cortés con astucia y cautela, sin fiarse únicamente de su valor personal: no de otra manera actuó en los episodios de la conquista registrados por la historia.

La figura de Cortés se recorta heroicamente en todo el relato, y, al concluir el episodio de la destrucción de las naves - decisión que se atribuye aquí exclusivamente al conquistador-, Zapata exclama, llevado de su entusiasmo (XIII, 38):

No creo que, puesto un hombre en tanto aprieto, ni africano, ni griego, ni de Roma, volviéndose atrás los siglos más de un día, tenido haya tanta osadía.

Con lo cual va más lejos aún que López de Gómara, su modelo, quien al narrar el mismo suceso, no obstante su admiración por Cortés, reconoce que ha tenido precedentes (ed. cit., p. 324b): "Pocos ejemplos déstos hay, y aquéllos son de grandes hombres, como fue Omich Barbarroja, del brazo cortado, que pocos años antes desto quebró siete galeotas y fustas para tomar a Bujía, según largamente yo lo escribo en las batallas de mar de nuestros tiempos".

Para sacar del sepulcro del olvido a los hombres que merecían eterna fama, escribió Juan de Castellanos las cuatro partes de que consta su voluminosa obra, con más de 140,00o versos. De Cortés y su empresa hace mención en dos elegías de la Primera parte ${ }^{18}$ : la vn, que tiene un solo canto, y la virr, que consta de tres. Del total de 192 octavas, no contamos las 94 que se dedican al naufragio de Alonso de Zuazo cuando fue enviado por Francisco de Garay como medianero ante Cortés ${ }^{19}$. Es de notar que, en realidad, ninguna de esas dos elegías se consagra expresamente al conquistador de México, sino, por el contrario, a dos hombres con quienes éste sostuvo pleitos y aun lucha armada por cuestiones tocantes a derechos de conquista y población, a saber, Diego Velázquez y Francisco de Garay. Castellanos promete consagrar a Hernán Cortés un canto especial para más tarde (vn, 14):

18 Por cierto que esta Primera parte es la que ofrece mayor interés literario. "Hay que distinguir... entre las diversas partes de la obra: la primera es poéticamente muy superior a las demás", dice Menéndez Pelayo, Antología..., ed. cit., t. 3, p. xv. Del mismo parecer son Parra, loc. cit., y Aída Cometta Manzoni, El indio en la poesía de América española, Buenos Aires, 1939, p. 68.

${ }^{19}$ Es éste uno de los pasajes que señala Menéndez Pelayo al reivindicar los méritos de Castellanos (cf. supra, nota 12). 
Pero terná particular tratado,

si Dios me diere vida suficiente,

cuando cante sus bríos y su maña

en lo que se dirá de Nueva España.

Pero el hecho es que no hay entre las Elegias un canto dedicado exclusivamente a Cortés y a la Nueva España, a menos que se acepte como tal la parte respectiva de la elegía viII, cosa improbable, ya que ésta se dedica expresamente "A la muerte del adelantado don Francisco de Garay, donde se escribe la isla Jamaica". Con todo, Castellanos, tal vez sin proponérselo, cumple aquí mismo su promesa.

Puesto que ha dedicado la elegía vn a exaltar la memoria de Velázquez, sería contradictorio pintarlo con las tintas deslucidas con que lo hace, por ejemplo, un Terrazas ${ }^{20}$. Así, pues, lejos de rebajar sus méritos, destaca su figura frente a la de Sebastián de Ocampo, su predecesor en la conquista de Cuba. Don Diego Colón -dice Castellanos- reconoció la habilidad de Velázquez:

El Ocampo no siendo tan bastante que pudiese vencer aquesta gente, don Diego, sucesor del Almirante, al Velázquez nombró por su teniente, para tales conquistas importante y en ellas muy cursado y excelente (vn, 4).

Pero, al mismo tiempo, el poeta atenúa con sutil discreción el relieve de esta hazaña, cuyo rápido éxito se debió más a la mansedumbre de los indios que a los esfuerzos de los españoles:

Sucedióle muy bien en la jornada

por no tener encuentros porfiados; y ansí, porque tuvieron riesgo poco, no hago mención dellos ni los toco (vir, 7).

Antes, en la primera octava de la elegía, Castellanos disculpa el hecho de que Velázquez, en vez de encargarse en persona de la empresa de México, haya dejado que Cortés la tomara por su cuenta. Pero, aunque lo disculpa, no deja de mencionarlo, con la ecuanimidad que da el haber tenido una azarosa vida de guerras y expediciones $^{21}$ :

${ }^{20}$ Dice Terrazas: "De todos sus amigos anda [Velázquez] esquivo, / viviendo melancólico, apartado; / muchos tiempos anduvo pensativo / y casi de las gentes afrontado. / Por una parte, el corazón altivo / le tiene de Cortés maravillado; / por otra, ver la empresa que así pierde / el ánimo de rabia le remuerde..."; "dormir no puede ya, y apenas come, / que humor de sus entrañas propias gasta; / y en su desvanecida fantasía / vido en visión la misma en que se v(e)ía". Para mayor abundamiento, véase el pasaje núm. 6 de la ed. de Castro Leal, que comienza "Sintió Diego Velázquez grande afrenta".

${ }^{21}$ Véase en PARRA, pról. cit., PP. vi-xxxiv, un exacto y sucinto resumen de la vida andariega de Castellanos. 
...Diego Velázquez, hombre venturoso

y que pudo tener mayor ventura,

si acaso por gozar ya de reposo

no perdiera sazón y coyuntura

fiando su poder y sus intentos

al capitán de grandes pensamientos (vn, 1$)$.

El poeta-cronista, deseoso de distribuir equitativamente la gloria del descubrimiento de la Nueva España, da relieve a las exploraciones de Hernández de Córdoba y Juan de Grijalva, predecesores de Cortés. Se ve en ello su esfuerzo por mantener una objetiva imparcialidad que redunde en loor del personaje a quien va consagrada la elegía. Sin embargo, la figura de Cortés se impone a cualquier intento de relegarla, siquiera sea de momento, y acaba por predominar. Castellanos, al contornear las hazañas y méritos de Velázquez o de Garay, logra efectos plásticos semejantes a los que resultan del desbaste en dos planos de una misma superficie. Sólo que aquí, una vez desbastado el hecho histórico común -expediciones, intentos de penetración en las costas de México-, Cortés queda como en alto relieve, mientras Velázquez y los demás permanecen en un lugar más discreto, aunque ciertamente importante. A diferencia de los otros capitanes a quienes Velázquez había ofrecido la dirección de la empresa, Cortés no vacila ante sus regateos y condiciones, como quien no las considerará inviolables llegado el caso; no es de extrañar, pues, que Velázquez se muestre arrepentido de habérsela confiado ya "antes de que partiese [Cortés] deste puerto". El resto de la elegía es una relación de lo acaecido entre Velázquez y Cortés una vez que éste se alza con la empresa de la conquista y determina llevarla a cabo por cuenta propia, sin dar parte más que a la Corona. A través del relato, la figura de Cortés se va afirmando mediante paralelos expresos o sobreentendidos. Veláz quez, dice el autor,

nombró por general y por tiniente, porque facilitaba la carrera, a Pánfilo Narváez el valiente, pero contra Cortés que más lo era (vn, 28 ).

Si Velázquez conquistó la isla de Cuba

con diestros y fortisimos soldados, sucedióle muy bien en la jornada por no tener encuentros porfiados (vn, 7).

Cortés, en cambio, inició sus operaciones en la costa

y por la tierra adentro no dormía, conquistando potentes principados, do con su breve copia de cristianos hacía siempre hechos soberanos (viI, 32). 
Si Velázquez se muestra atrabiliario ("Respondióle Velázquez de mal arte...") y Narváez procede con escaso tacto, enajenándose la voluntad del oidor Lucas Vázquez de Ayllón y de los vecinos de Villa Rica, Cortés aparece como un paciente diplomático que agota todos los medios antes de recurrir a la violencia:
$Y$ ansí, por evitar sangrienta mano, tentó medios de paz como cristiano...
Escribióle por términos debidos, haciendo generoso cumplimiento, y con honorosísimos partidos huyendo de venir en rompimiento; pero Narváez, con la gran pujanza, remitió los partidos a la lanza (vu, 35-36).

Al no ver otra solución que la de las armas, Cortés - "varón de paz y guerra"- no se arredra por más que tenga una desventaja inicial. Narváez ha llegado "con soberbia lozanía" (vII, 32); la gente de Cortés, menor en número, es en cambio "más valiente que lucida" (vII, 38); Narváez llega con una imponente cantidad de pertrechos y hombres;

Cortés, aunque con ánimo más alto,

de todas estas cosas vino falto (vn, 39).

Cuando Velázquez, tras la sonada derrota de su lugarteniente, decide encargarse en persona de someter a Cortés, su impotencia es palpable:

$$
\begin{aligned}
& \text { Juntó navios bien aderezados } \\
& \text { de todos los pertrechos que convino, } \\
& \text { y en ellos grande copia de soldados; } \\
& \text { pero por parecelle desatino, } \\
& \text { a vista de los puertos deseados } \\
& \text { tuvo por bien volverse del camino (vn, } 46 \text { ). }
\end{aligned}
$$

La figura de Hernán Cortés, siempre engrandecida, emerge hasta del lacónico epitafio de Velázquez con que se cierra este episodio:

$$
\begin{aligned}
& \text { Aquí está en lugar estrecho } \\
& \text { quien tuvo larga ventura } \\
& \text { y, en tiempo de más provecho, } \\
& \text { por mano de su hechura } \\
& \quad \text { fue deshecho. }
\end{aligned}
$$

La dedicatoria de la elegía vn y una primera impresión de su lectura despistaron quizá al concienzudo Menéndez Pelayo, quien no vio en ella sino un elogio de Velázquez y hasta subraya la singularidad del caso $^{22}$. Que el verdadero sentimiento de Castellanos, difícilmente

${ }^{22}$ Menéndez Pelayo, Antología, ed. cit., t. 2, p. iv: "Entre los conquistadores tampoco hubo quien celebrase las empresas del adelantado Diego Veláz- 
reprimido, es el que hemos puesto de relieve en nuestra interpretación, puede comprobarse con la lectura de otros pasajes en que el poeta no está constreñido por una dedicatoria. Así en éste (II, I, $2,27-28)$ :

Pudiera dar ejemplos de pasados que fueran a propósito traídos, de pobres diligentes levantados, de prósperos ociosos abatidos; Tuburlanes de gloria coronados, Dionisios de corona despedidos: pero basta traer a consecuencia aquello que se ve por esperiencia.

E1 bien que la fortuna le ofrecía perdió Velázquez por su negligencia, y con Cortés usó de cortesía, aunque dijeron ser inobediencia; mas es gran vanidad y bobería de gentes que no tienen advertencia, pues no fueron sus hechos soberanos ocasiones soltando de las manos.

Poco más adelante (II, III, I, I52), cuando un grupo de españoles recuerda, para darse ánimo en la adversidad, casos de desventaja numérica, el nombre de Cortés adquiere casi una connotación antonomástica:

Éntre Fernán Cortés en estos cuentos, que con más breve copia de varones venció tales rencuentros y tan agros, que podemos contallos por milagros.

No se le ocultó a Gabriel Lobo Lasso de la Vega la consecuencia elogiosa para Cortés de esos versos de las Elegías, y así incluyó en sus Elogios en loor de los tres famosos varones (I60 I), varias de las octavas que se refieren a Velázquez ${ }^{23}$.

A la elegía vn de Castellanos, que acabamos de analizar, sigue la dedicada a Francisco de Garay. Aquí la preeminencia de Cortés es aún más patente. El empeño de emular al conquistador de México incrusta fatalmente a Garay en un segundo plano, tanto más reducido cuanto que hay lugar para una comparación directa. Aunque

quez de Cuéllar, a quien, no obstante, Juan de Castellanos dio lugar en su panteón de Varones ilustres de Indias, consagrándole integra una elegía, que es la séptima".

${ }^{23}$ Elogios en loor de los tres famosos varones don Jaime rey de Aragón, don Fernando Cortés marqués del Valle y don Álvaro de Bazán marqués de Santa Cruz. Las octavas incluidas son cuatro: "Mayormente Cortés que bien mirado" (fol. 62 v $\mathrm{v}^{\circ}$ ), "Mas Fernando Cortés varón experto", "Quedó Diego Velázquez con tristura" (fol. $63 \mathrm{r}^{\circ}$ ) y "Llegó pues con souerbia lozanía" (fol. $63 \mathrm{v}^{\circ}$ ). 
ya había hecho otras expediciones ${ }^{24}$, el buen éxito de Cortés es un poderoso acicate para hacerle intentar nuevas empresas,

pues visto que Cortés descubrió senos

de tan engrandecidas poblaciones,

juzgó de su persona no ser menos

para tener tan altas pretensiones (vm, 1, 8).

Se hace, pues, a la mar, bien pertrechado y con ánimo de poblar en la región del Pánuco, donde ya antes había fracasado en tentativas semejantes. Al llegar a Cuba se entera de que Cortés, con su habitual diligencia, se le ha adelantado. Garay, que tiene título para ello, insiste en su proyecto, mas no sin antes enviar como emisario al licenciado Alonso de Zuazo, para evitar rencillas. Aquí el poeta se desvía de su propósito inicial y narra en noventa y dos octavas las desventuras de Zuazo. Pero no será en balde: con motivo del rescate del licenciado y sus gentes, el autor encuentra ocasión de presentar a Cortés generoso y hospitalario, así como conocedor de hombres y ganador de voluntades, pues atrae a Zuazo a su causa y lo nombra lugarteniente suyo mientras él se dirige a las Hibueras para castigar la insurrección de Cristóbal de Olid.

El tercer canto de esta elegía vin se ocupa enteramente de Francisco de Garay. La expedición es un desastre. Los pueblos indios donde pensaba avituallarse han sido asolados por Cortés (vIrI, 3, 6), quien de ese modo ha castigado la hostilidad de sus pobladores, apresurando al mismo tiempo su pacificación. Garay encamina a su gente a cierto punto para fundar allí un pueblo, pero lo encuentra ya ocupado por Santisteban del Puerto, fundación de Cortés:

Allí donde la proa todos llevan

en fundar población con su consejo,

estaba ya fundado Santisteban,

por capitán un Pedro de Vallejo (virI, 3, 7).

Grijalva, encargado de la parte marítima de la expedición, pierde cuatro de sus once navios, y otros se rinden al capitán de Cortés. El grupo que avanza por tierra es atacado por los indios y sufre mil calamidades. Las arengas de Garay no consiguen detener las deserciones, pues

los más, a causa del provecho, tenían a Cortés dentro del pecho.

Porque costumbre fue de señoríos que quien más puede, tiene más devotos (vm, 3, 9-10).

${ }^{24}$ Las expediciones anteriores son de 1518 y 1519 ; la que relata Castellanos es la de 1529. Ninguna de ellas fue afortunada. Cf. López de Gómara, His toria general de las Indias, BAAEE, t. 22, p. 183a, y Conquista de México, ed. cit., p. $397 a b$. 
Garay, que con tantas ínfulas había salido de Jamaica, tiene que ir finalmente a hablar con Hernán Cortés,

para que capitán tan escelente

hiciese lo que dél se confiaba

en la restauración de su caída,

de su reputación y de su vida (viu, 3, 23).

El epitafio con que concluye la elegía es aún más revelador. Inconscientemente, Castellanos vuelve a establecer un parangón que resulta desfavorable para el destinatario de la elegía y elogioso en última instancia para su antagonista:

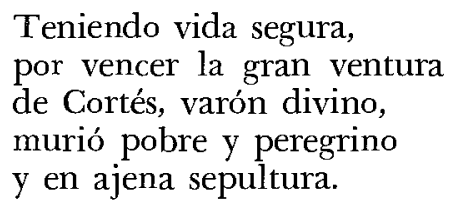

Interpretándolo así, Lobo Lasso de la Vega incluirá también el epitafio de Garay entre las alabanzas al conquistador de México que incluye en sus Elogios (op. cit., fol. $63 \mathrm{v}^{0}$ ).

El poema de Castellanos se mantiene dentro de los límites de sus fuentes históricas. Parra, aludiendo en el prólogo de su edición a las investigaciones de $\mathrm{Caro}^{25}$, menciona varias obras, hoy perdidas, como fuentes secundarias, y la de Fernández de Oviedo como principal, sin aludir a López de Gómara. En lo que se refiere a las dos elegías aquí estudiadas, un cotejo de ambas fuentes muestra a las claras que el modelo de Castellanos es sobre todo el libro de Gómara. De la Conquista de México de este autor toma el poeta de las Elegias, por ejemplo, varios detalles de la disensión entre Cortés y Velázquez y de la escaramuza con Narváez, que faltan en Oviedo. Lo que sucede es que Castellanos, cronista minucioso, sigue al historiador que mejor satisface su sed de detalles; por eso, en el episodio del naufragio de Zuazo, abandona a Gómara, que sólo le dedica unos párrafos, y sigue a Oviedo, quien narra el naufragio con lujo de circunstancias $^{26}$. Si alguna vez se aparta Castellanos de sus fuentes, se trata de un desliz minúsculo, provocado tal vez por una rima difícil ${ }^{27}$, pero sin trascendencia en cuanto a la caracterización

${ }^{25}$ Parra, pról. cit. Los estudios de Miguel Antonio Caro, publicados en el Repertorio Colombiano, 1879 y 1880 , constituyen ahora el prólogo a las Obras de Castellanos, ed. de Bogotá, 1955.

${ }^{26}$ C.f. López de Gómara, Conquista de México, ed. cit., p. 399ab, y GoNzalo Fernández de Oviedo, Historia general y natural de las Indias..., ed. J. Amador de los Ríos, t. 4, Madrid, 1855, pp. 482 ss.

${ }^{27}$ Así, al narrar el encuentro con Narváez, la necesidad de rima para faleo. nete le hace declarar que fueron "diez y siete" los muertos de Narváez. Cortés dice que su enemigo "tenía a la escalera de [la torre] hasta diez y nueve tiros de fusilería", pero en un párrafo astutamente ambiguo resta importancia a las 
de los personajes o al tono del poema. Ha desaparecido el residuo caballeresco que hemos visto en Zapata, con proyección hacia lo fantástico, y sólo queda la historia escueta. Para un nuevo aunque tenue aleteo fuera de la historia, habrá que esperar el poema de Gabriel Lobo Lasso de la Vega.

Brown University.

J. Amor y VázQuez

bajas: "sin muerte de hombres, más de dos que un tiro mató, en una hora eran presos todos los que se habían de prender" (Segunda carta de relación, $B A A E E$, t. 22, p. 40a). López de Gómara no sabe exactamente cuántos eran los tiros de fusilería: "y a la puerta trece tiros, o según otros dicen, diecisiete", pero es terminante en cuanto a las bajas: "Murieron dieciséis de la parte de Narváez, y de la de Cortés dos solamente, que mató un tiro". - Generalizando sobre la inspiración del Beneficiado de Tunja, dice Menéndez Pelayo (Antologia..., ed. cit., t. 3, p. lvi) que no fue "tan alta que por razones de metro no se viera con frecuencia en el caso de oscurecer la verdad o de interpretarla en un sentido completamente vago, cuando no de agraviarla en gracia de licencia poética..." - No estará de más advertir que en la totalidad del poema de Castellanos se encuentran indicios de las corrientes imaginativas y novelescas suscitadas por el descubrimiento de América. Véase lo que dice Antonıo CuRcro Altamar, "El elemento novelesco en el poema de Juan de Castellanos", $B I C C, 8$ (1952), p. 83: "De reconocer es en él... su profundo sentido de verismo, en el marco, claro es, de las propias modalidades narrativas. Desde un principio también, y en constancia del realismo veraz de este escritor, quiero poner de resalto cómo en su obra quedan recusadas siempre las «supercherías», y que se acude en consonancia con la mentalidad hispánica del tiempo a buscar en la raíz de los fenómenos increíbles, pero admitidos por el autor, una fundamentación en el supramundo, en una realidad doble, sensible y sobrenatural, que palmaria y eficazmente se entrecruza". 